\title{
The moisture buffer capacity of biomass concretes based on rapeseed straw
}

\author{
Maya HAJJ OBEID ${ }^{\mathrm{a}}$, Omar DOUZANE ${ }^{\mathrm{a}}$, Lorena FREITAS DUTRA ${ }^{\mathrm{a}}$, Geoffrey PROMIS ${ }^{\mathrm{a}}$, Anh Dung \\ TRAN LE ${ }^{\mathrm{a}}$, Boubker LADOUDI ${ }^{\mathrm{b}}$, Thierry LANGLET ${ }^{\mathrm{a}}$ \\ ${ }^{a}$ Innovatives Technologies Laboratory (LTI), University of Picardie Jules Verne, Avenue des Facultés - 80025 Amiens Cedex 1, France. \\ ${ }^{b}$ CoDEM Picardie, 56 Rue André Durouchez, 80080 Amiens, France.
}

\begin{abstract}
Biomass materials are increasingly being used in both new buildings and renovation work owing to their low energy impact and their good hygrothermal properties. In this paper, a dynamic characterization of hygric behavior of two different rapeseed concrete, an insulating and loadbearing material, is presented. The moisture buffer value (MBV) is measured according to the NORDTEST protocol. Samples are exposed to daily cyclic variation of relative humidity: $8 \mathrm{~h}$ at $75 \% \mathrm{RH}$ and $16 \mathrm{~h}$ at $33 \% \mathrm{RH}$ at $23^{\circ} \mathrm{C}$. Results show an excellent $\mathrm{MBV}$ value for the insulating material and a good MBV value for the load-bearing insulating material. Peer-review under the responsibility of the organizing committee of the ICMB21.

Keywords: building physics, moisture, hygroscopic materials, relative humidity, moisture buffering.
\end{abstract}

\begin{tabular}{|ll}
\hline Nomenclature \\
MBV & Moisture Buffer Value $\left[\mathrm{g} / \mathrm{m}^{2} \% \mathrm{RH}\right]$ \\
$\Delta m$ & Moisture uptake/release during the period $[\mathrm{g}]$ \\
$\mathrm{RH}$ & Relative humidity $[\%]$ \\
$\mathrm{A}$ & Open surface area $\left[\mathrm{m}^{2}\right]$
\end{tabular}

\section{Introduction/Background}

The selection of materials used in the construction process plays an important role in reducing environmental pollution. Therefore, innovative solutions have been implemented, such as manufacturing very porous materials that consume less energy and are more environmentally friendly, known as "biomass materials". These innovative materials are increasingly used both in new buildings and in renovation work thanks to their low energy impact.

This study is, therefore, dedicated to investigate the ability of new concretes formulated with vegetable aggregates, especially rapeseed straw, to moderate cyclical variations in moisture and humidity and the coupling effect of static temperature conditions with dynamic humidity conditions.

\section{Methodology}

\subsection{Materials}

In this paper, two innovative building materials based on rapeseed concrete are studied. First type is a non-load-bearing isolation (BINP) composed of water, rapeseed straw, lime and cement. Second type is a load-bearing insulating concrete (BIP) consisting of a normal concrete mixed with a rapeseed straw. The aggregates used in this study measure $25 \mathrm{~mm}$.

Physical and dimensional characteristics such as density, exchange surface and depth were measured for each material type and are presented in table 1. BIP specimen's size is $10 \mathrm{~cm} \times 10 \mathrm{~cm} \times 5 \mathrm{~cm}$ (exchange surface is $100 \mathrm{~cm}^{2}$ ). For BINP, dimensions are: $10 \mathrm{~cm} \times 10 \mathrm{~cm} \times 7 \mathrm{~cm}$ (exchange area is $100 \mathrm{~cm}^{2}$ ). The samples are conditioned at a temperature of $23^{\circ} \mathrm{C}$ and a relative humidity of $50 \%$ before starting the MBV cycle.

Table 1 : Physical characteristics of BINP and BIP materials

\begin{tabular}{llcc}
\hline & Density $\left(\mathbf{k g} / \mathbf{m}^{\mathbf{3}}\right)$ & Exchange surface $\left.\mathbf{( m}^{\mathbf{2}}\right)$ & Depth $(\mathbf{m})$ \\
\hline BINP & 522 & 0.01 & 0.08 \\
\hline BIP & 1280 & 0.01 & 0.05 \\
\hline
\end{tabular}

\subsection{Methods}

The Moisture Buffer Value (MBV) is an index of the amount of water vapor that a material can store. An experimental protocol has been set up by the NORDTEST [1] project, in order to calculate the hygroscopic inertia of hygroscopic materials.

(C) The Author(s). This is an open access article distributed under the terms of the Creative Commons Attribution Licence (CC BY) 4.0 https://creativecommons.org/licenses/by/4.0/, which permits unrestricted use, distribution and reproduction in any medium, provided the original author and source are credited. DOI: 10.14293/ICMB210081 


\section{ICMB21}

The principle of this test protocol is to submit samples to different relative humidity cycles over time in order to get closer to the cycles found in buildings. Samples are subjected to cycles of $8 \mathrm{~h}$ and $16 \mathrm{~h}$ corresponding to relative humidity values of $75 \%$ and $33 \%$ respectively until a state of equilibrium is reached.

$$
M B V=\frac{\Delta m}{A\left(R H_{\text {high }}-R H_{\text {low }}\right)}
$$

The classification of the moisture buffer value is given in 5 categories ranging from $0(\mathrm{~g} /(\mathrm{m} 2 \% \mathrm{RH})$ to $3.5(\mathrm{~g} /(\mathrm{m} 2 \% \mathrm{RH})[1]$.

Biomass materials rank among the excellent values $(>2 \mathrm{~g} / \mathrm{m} 2 \% \mathrm{RH})$. In particular, the moisture buffer value of rapeseed concrete in the literature is around $2.59 \mathrm{~g} / \mathrm{m} 2 \% \mathrm{RH}[2]$.

\section{Results}

The histogram (Figure 1) summarizes different experimental moisture buffer values found in literature and obtained in this study. It can be seen that BIP and BINP presented good and excellent moisture buffer capacities respectively according NORDEST project [1]. BINP value, $2.96 \mathrm{~g} / \mathrm{m} 2 \% \mathrm{RH}$, is even higher than the hemp concrete MBV calculated by Evrard [3] by Collet [4] and the rapeseed concrete value found by Rahim [2]. Concerning BIP value, $1.82 \mathrm{~g} / \mathrm{m} 2 \% \mathrm{RH}$, it also presents a good performance compared to the same type of conventional concrete (load-bearing) in literature: $0.4 \mathrm{~g} / \mathrm{m} 2 \% \mathrm{RH}$ [1] and the low weight concrete $0.8 \mathrm{~g} / \mathrm{m} 2 \% \mathrm{RH}$ [1]. Therefore, the addition of rapeseed straws clearly increases materials absorption and desorption capacity.

Density and porosity consequently can also have an influence on the hygroscopic buffer capacity. It can be noticed in table 1, the density difference regarding BIP and BINP samples which confirms that a less dens (more porous) material tends to adsorb and release moisture better than a denser material. Thickness can also play an important role in moisture buffer capacity since BINP has a greater thickness than BIP.

Besides the excellent MBV, BINP also shows a fast stability regarding mass variation as a function of moisture variation between $33 \%$ and $75 \%$ (Figure 2). Indeed, remarkably, BINP mass variation is stable from the fourth relative humidity cycle on.

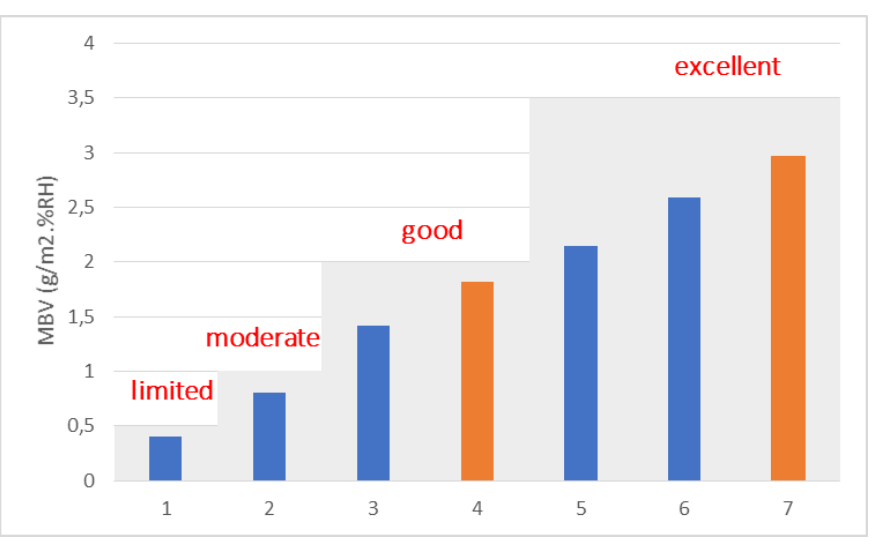

Figure 1: MBV value - experimental study and literature

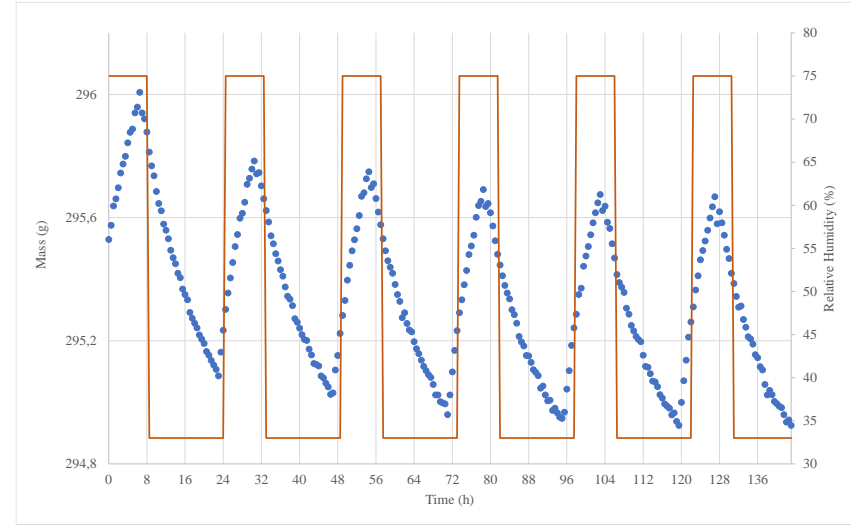

Figure 2: variation of mass over the time $\%$ RH cycle of BINP

\section{Conclusion}

In the present work, the dynamic hygric behavior of two materials (BINP and BIP) based on rapeseed straw is investigated experimentally. The first material (BINP) is considerate as an insulator has an excellent moisture buffer value. The second type (BIP) is considerate a load-bearing concrete isolation and presented a good moisture buffer value.

The experimental set-up is validated by comparison of MBV values given in the NORDTEST project and literature. Results show that the rapeseed straw concretes have a better moisture buffering capacity than hemp concrete. Therefore, these biomass materials can be excellent hygric regulators that improve hygrothermal comfort and reduces energy needs.

\section{Reference}

[1] Roels, S., \& Janssen, H. (2006). A comparison of the Nordtest and Japanese test methods for the moisture buffering performance of building materials. Journal of Building Physics, 30(2), 137-161.

[2] Rahim, M. (2015). Analyse et caractérisation du comportement hygrothermique de parois agro-sourcées à l'échelle 1: expérimentation et modélisation (Doctoral dissertation, Amiens).

[3] Evrard, A. (2008). Transient hygrothermal behaviour of lime-hemp materials. Universite Catholique De Louvain.

[4] Collet, F., \& Pretot, S. (2014). Thermal conductivity of hemp concretes: Variation with formulation, density and water content. Construction and building materials, 65, 612-619. 